\title{
PRIMENA POTPORNIH KONSTRUKCIJA U ULICI BRAĆE ANĐELIĆ U SREMSKIM KARLOVCIMA
}

\section{USING RETAINING WALL CONSTRUCTIONS IN BRAĆE ANĐELIĆ STREET IN SREMSKI KARLOVCI}

\author{
Dejan Palalić, Fakultet tehničkih nauka, Novi Sad
}

\begin{abstract}
Oblast - GRAĐEVINARSTVO
Kratak sadržaj - U radu su opisani potporni zidovi, njihova podjela i namjena. Fokus je na armirano betonskim gravitacionim zidovima za koje je opisano konstruisanje. Takođe, za gravitacione zidove navedena je geostatička analiza. Zatim su u kratkim crtama opisani rezultati projektovanja potpornih zidova u ulici Braće Anđelić koja se nalazi u Sremskim Karlovcima.
\end{abstract}

Ključne reči: potporni zidovi, $A B$ zidovi

Abstract - In this paper we described retaining walls, their partition and purpose. The focus is on reinforced concrete walls and theirs construction. Also, we showed geostatic analysis for them. In addition, we described briefly results of retaining wall design in Braće Anđelic street in Sremski Karlovci.

Keywords: retaining walls, reinforced concrete walls,

\section{UVOD}

Čovjek od davnina teži da sredinu u kojoj živi prilagodi svojim potrebama. To je izvorni motiv za razvoj građevinarstva. Potporne konstrukcije su konstrukcije čija je primarna uloga podupiranje tla, trupa puta ili brdske ili neke druge mase ili zadržavanje vode. Ovakve konstrukcije omogućavaju da teren bude izveden pod strmijim nagibom u odnosu na prirodni nagib tla. Koriste se za privremeno ili trajno podupiranje zemlje ili nekog drugog materijala u slučaju da je obezbjeđenje priro-dnog nagiba neizvodljivo.

Podjela potpornih konstrukcija na osnovu [1]:

- $\mathrm{u}$ pogledu eksploatacije postoje trajne i privremene potporne konstrukcije

- u pogledu položaja uz put postoje konstrukcije koje podupiru trup puta i konstrukcije koje podupiru padinu iznad puta

- u pogledu krutosti postoje krute i deformabilne potporne konstrukcije

- u pogledu funkcije u prostoru razlikujemo konstrukcije za zadržavanje, podupiranje tla $\mathrm{i}$ brdskih padina $\mathrm{i}$ zadržavanje vode

- u pogledu načina i tehnologije izvođenja razlikujemo potporne konstrukcije izgrađene $\mathrm{u}$ otvorenoj građevinskoj jami sa iskopom po kampadama, potporne konstrukcije građene sa površine terena odozgo nadole po kampadama po dužini i fazama.

\section{NAPOMENA:}

Ovaj rad proistekao je iz master rada čiji mentor je bio dr Miloš Šešlija, docent.
Prema [2] otporni zidovi se mogu podijeliti na masivne (gravitacione), konzolne, konstrukcije fundirane na šipovima, zidove sa kontraforom i usidrene zidove.

Za svaki od navedenih tipova zidova postoje karakteristični tipovi opterećenja, a samim tim i karakteristični lomovi. Neki od njih prikazani su na slici 1.

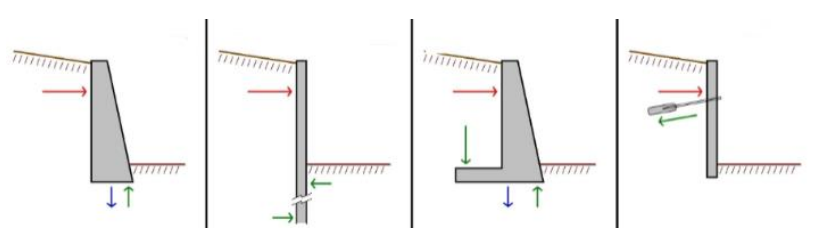

Slika 1. Međusobno djelovanje konstrukcija-teren

Kako se u okviru ovog projekta koriste armirano-betonski potporni zidovi, akcenat rada će biti upravo na ovoj kategoriji potpornih konstrukcija.

\section{ARMIRANO BETONSKI GRAVITACIONI ZIDO- VI}

Armirano betonski gravitacioni zidovi su zidovi koji su u odnosu na nearmirane betonske gravitacione zidove ojačani armaturom. Ovakav koncept zasnovan je na racionalizaciji materijala jer su $\mathrm{AB}$ zidovi mnogo manjih dimenzija u odnosu na standardne gravitacione zidove. Ovakve konstrukcije u suštini imaju istu ulogu kao i nearmirani betonski zidovi, samo je način naprezanja i prihvatanja opterećenja drugačiji u odnosu na nearmirane betonske zidove.

AB gravitacioni zidovi se izvode od betona min C25/30 i armature koja se određuje na osnovu dimenzionisanja kritičnih presjeka. AB gravitacioni zidovi se u odnosu na nearmirane gravitacione zidove koriste kada su u pitanju ograničenja u prostoru i u drugim slučajevima kada je to ekonomski opravdano. Oni se koriste i kada je temeljno tlo loše (u pogledu nosivosti), kada masivne konstrukcije ne mogu da zadovolje kriterijum nosivosti temeljnog tla. $\mathrm{AB}$ zidovi su ekonomični u smislu smanjenja količine betona i prikladni su za tla manje nosivosti jer velika površina temelja smanjuje pritisak na temeljno tlo. Dodatno smanjenje tj. povoljniji raspored pritisaka garantuju izvedena rebra (podupirači). Poseban tip AB ugaonih zidova su zidovi sa rebrima za ojačanje na zaleđnoj strani. Povoljni su za zidove većih visina pošto 
se njihovom upotrebom smanjuju dimenzije i količina potrebne armature, naponi i deformacije [1].

\subsection{Konstruisanje armirano betonskih gravitaionih zidova}

AB gravitacioni zidovi se konstruišu sa nešto strmijim nagibom u odnosu na betonske gravitacione zidove. Nagiv čeone strane je od 5:1 - 10:1, odnosno vertikalno. Leđna strana je po pravilu vertikalna, ali ne mora biti. Kod AB gravitacionih zidova se sa čeone strane izvodi raširenje tla.

Kada su u pitanju ugaoni $\mathrm{AB}$ zidovi, to raširenje se izvodi i sa čeone i sa leđne strane [1].

Minimalna debljina AB gravitacionog zida je $0.40 \mathrm{~m}$ i ona se povećava sa visinom. Nagib donje ravni temeljne ploče se izvodi u granicama 10-20\% (1:10 - 1:5) prema leđnoj strani. Nagib gornje ravni temeljnih peta je $2 \%$ od čeone stijene odnosno leđne stijene u slučaju $\mathrm{AB}$ ugaonog zida. Visina temelja na kontaktu sa stijenom jednaka je debljini stijene na tom dijelu.

Dubina temeljenja definisana je na osnovu dubine smrzavanje i geoloških karakteristika terena. Ako se konstrukcije izvode u vodi, minimalna dubina temeljenja je $1.50 \mathrm{~m}$ ili se temelj ukopa u stijensku masu u dubini od 0.5-1.0m [1].

\section{GEOSTATIČKA ANALIZA GRAVITACIONIH KONSTRUKCIJA}

Geostatička analiza se zasnva na ispitivanjima (terenskim i laboratorijskim) i na prostorno- urbanističkih, saobraćajnih, hidrološko- hidrotehničkih, klimatskih i seizmoloških podataka. Nakon svega navedenog, potrebno je ispitati (dokazati) granična stanja nosivosti, upotrebljivosti i trajnosti.

\subsection{Granična stanja nosivosti}

U geostatičkoj analizi su obuhvaćene sve projektne situacije (stalne, povremene, incidentne i seizmičke) u toku izgradnje, upotrebe, održavanja i u vanrednim situacijama za ukupni vijek trajanja konstrukcije:

- gubici globalne konstrukcije

- lom tla

- pomjeranje temelja

- preturanje

- lom konstrukcijskih elemenata.

\subsubsection{Dokaz graničnih stanja nosivosti AB gravitacion-} ih konstrukcija

Da bi uslov u pogledu graničnih sranja nosivosti bio ispunjen, potrebno je da bude zadovoljeno:

$$
E_{d, u} \leq R_{d, u}
$$

gdje je $E_{d, u}$ proračunska vrijednost uticaja, a $R_{d, u}$ proračunska nosivost konstrukcije.

Projektne vrijednosti uticaja i projektne vrijednosti otpora se određuju pomoću parcijalnih koeficijenata sigurnosti. Postoje parcijalni koeficijenti za dejstva $\left(\gamma_{F}\right)$ koji uvećavaju vrijednost dejstva da bi bili na strani sigurnosti i parcijalni koeficijenti za materijal $\left(\gamma_{M}\right)$ koji smanjuju stvarnu nosivost materijala iz istog razloga [3].

Osim navedenih postoje još parcijalni koeficijent učinka dejstva $\gamma_{E}$ i parcijalni koeficijent otpora $\gamma_{R}$. U zavisnosti od kombinacije korišćenih koeficijenata postoje tri različita prostupa u okviru statičke analize.

Karakteristične vrijednosti su vrijednosti koje su izabrane na osnovu rezultata ispitivanja i na osnovu računske vrijednosti, one mogu biti više ili manje od dobijenih. U proračunu se koristi najnepovoljnija kombinacija vrijednosti. Projektne vrijednosti se računaju kao količnik karakteristične vrijednosti i koeficijenata sigurnosti za određeni materijal.

\subsection{Pritisci tla}

\subsubsection{Vertikalni pritisci tla}

Pritisak tla na konstrukciju proizilazi iz vertikalnog pritiska koji je posljedica težine samog tla iza zida (gravitacione sile). Vertikalni pritisak zavisi od dubine na kojoj ga posmatramo, površinskog opterećenja i karakteristike tla. U matematičkom smislu to je:

$$
P_{v}=q+\gamma h\left(k N / m^{2}\right) .
$$
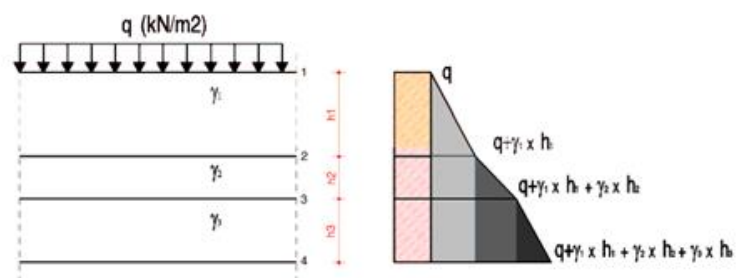

Slika 2. Dijagram pritisaka na slojevito tlo

Kada u tlu imamo vodu, onda se neutralni napon $\gamma_{w} \cdot h$, koji ne izaziva slijeganje, prenosi porama $u$ svim pravcima jednako, a efektivni napon $h_{z}\left(\gamma_{z}-\gamma_{w}\right) \mathrm{u}$ tlu se prenosi dodirnim površinama čvrstih čestica.

\subsubsection{Horizontalni pritisci tla}

Horizontalni prisitak tla se takođe povećava sa dubinom, samo je priraštaj te funkcije različit u odnosu na vertikalni pritisak

$$
P_{h}=K \cdot \gamma \cdot h\left(k N / m^{2}\right)
$$

a u slučaju da imamo i dodatno opterećenje $q$, izraz će izgledati

$$
P_{h}=K \cdot(q+\gamma \cdot h)\left(k N / m^{2}\right)
$$

gdje je $K$ koeficijent horizonzalnog pritiska tla.

U zavisnosti od pomjeranja konstrukcije postoje: mirni pritisci tla $p_{0}$ (konstrukcija se ne pomjera ili su pomjeranja zanemarljiva), aktivni pritisci tla $p_{a}$ (konstrukcija se pomjera od tla) i pasivni pritisci tla $p_{p}$ (konstrukcija se približava tlu). Važi

$$
k_{a}<k_{0}<k_{p}
$$

Treba naglasiti da su potporni zidovi skupe konstrukcije i da je važno posebno pažnju posvetiti njihovom projektovanju i izvođenju.

Detaljna ispitivanja tla na kojem se gradi potporna konstrukcija predstavljaju polaznu fazu projektovanja i na osnovu njih dobijamo ulazne podatke za projektovanje. Jasno je da bez tačnih podataka nije moguće kvalitetno isprojektovati, a samim tim ni izvesti konstrukciju. 
$\mathrm{Na}$ slici 3 vidi se jedan primjer pogrešno izvedene potporne konstrukcije.

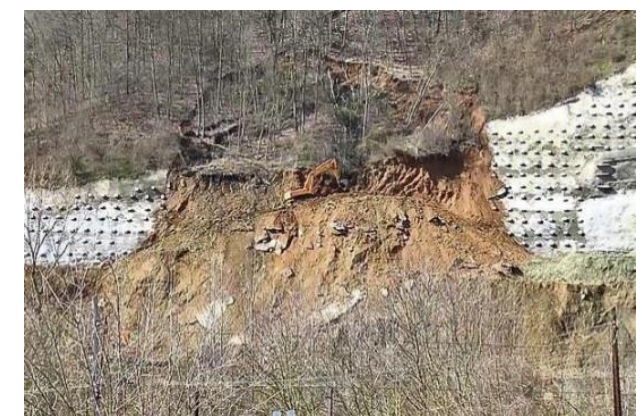

Slika 3. Primjer rušenja potporne konstrukcije [4]

\section{PROJEKTOVANJE POTPORNIH ZIDOVA U ULI-CI BRAĆE ANĐELIĆ \\ 4.1. Predmetna lokacija}

Ulica Braće Anđečić je saobraćajnica kroz stambenu zonu Sremskih Karlovaca širine 3.0-4.5m. Ukupna dužina osovine ulice je $844.40 \mathrm{~m}$. Osovina ulice je definisana od raskrsnice sa ulicom Patrijarha Rajačića do raskrsnice sa ulicom Karlovačkih đaka, slika 4.

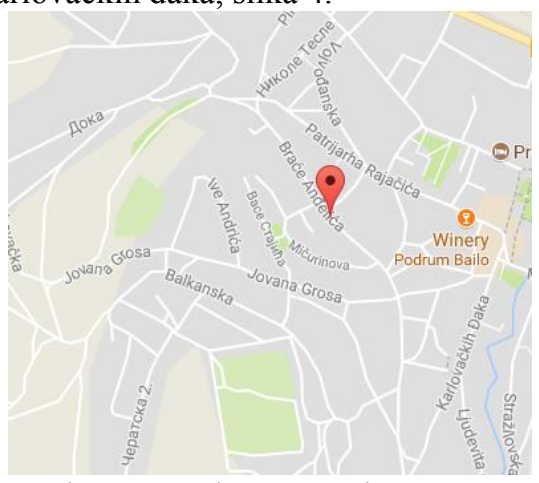

Slika 4. Lokacija predmetne saobraćajnice [Google Maps]

Predmetnu lokaciju karakterišu veliki podužni i poprečni padovi terena. Opština Sremski Karlovci nalazi se na desnoj obali Dunava podno Fruške Gore, $12 \mathrm{~km}$ jugoistočno od Novog Sada [5].

\subsection{Novoplanirano stanje}

Kako se kroz ovu ulicu planira prolaz autobusa, predviđen je kolovoz širine $5.5 \mathrm{~m}$. Samo je na početku kolovoz širine $3.0 \mathrm{~m}$, odnosno do $3.5 \mathrm{~m}$, kroz krivinu $\mathrm{R}=55 \mathrm{~m}$. Poprečne ulice su priključene lepezama radijusa $\mathrm{R}=2-50$ $\mathrm{m}, \mathrm{u}$ zavisnosti od raspoloživog slobodnog prostora.

Osovina kolovoza je položena u središnom dijelu regulacije, odnosno tako da budu sa obe strane staze minimalne širine i gdje je bilo više prostora, da bude moguće formiranje zelenog pojasa širine $1.5 \mathrm{~m}$. Promjena pravaca osovine su zaobljavani kružnim krivinama radijusa $\mathrm{R}$ =30-550 m. Ukupna dužina definisane osovine je 844.40 m.

Trotoari su promjenljive širine, $\mathrm{u}$ skladu sa regulacijom koja je na raspolaganju projektantu. Na zahtjev investitora, na pojedinim mjestima su trotoari ostavljeni širine 40-50 cm, kako to prostor dozvoljava. Zbog bezbjednosti pješaka, planira se režim usporenog saobraćaja što će se usloviti saobraćajnim znacima i izdignutim platformama za kretanje pješaka.
Niveleta kolovoza je položena prema uslovu odvodnjavanja svih površina u regulaciji ove ulice preko kolovoza i uslova maksimalnog uklapanja kolskih ulaza. Ovakav pristup zahtijeva izgradnju atmosferske kanalizacije, koja bi prihvatala svu vodu iz ulice Braće Anđelić i vodu iz priključnih ulica koja gravitira ka ovoj ulici.

S obzirom da postoji velika denivelacija u odnosu na okolni teren projektovani su potporni zidovi kako bi se stabilizovao nasip. Potporni zid se izvodi od betona $\mathrm{MB}$ 30, armiran je armaturnim mrežama MAG 500/560 i rebrastom armaturom B500B.

Zidovi su ukupne dužine 130 m i izvode se iz kampada, koje se međusobno dilatiraju. Potporni zidovi se fundiraju na kosoj podlozi, na tamponu betona MB15 d=5 cm i tamponu šljunka $\mathrm{d}=30 \mathrm{~cm}$. Da bi se vršila drenaža terena $\mathrm{u}$ zaleđu potpornog zida, u zid se na rasteru od po $1.30 \mathrm{~m}$ ugrađuju barbokane od PVC cevi Ø50, iza kojih se izrađuje drenažni zasip od iberlaufa, oko kojeg se postavlja geotekstil 300 gr.

Potporni zid PZ1: Dužina zida je $37.62 \mathrm{~m}$. Sastoji se iz dva segmenta. Donja ploča zida je širine $1.90 \mathrm{~m}$ i visine $0.25 \mathrm{~m}$. Zid je zid je konstantne visine $2.75 \mathrm{~m}$ i debljine $30 \mathrm{~cm}$.

Potporni zid PZ2: Zid se sastoji iz šest dijelova. Zbog promjene nivelacije segmenti zida su fundirani na različitim dubinama i različite su visine zidova. Visina prvog segmenta $2.20 \mathrm{~m}$, dužina zida $4.20 \mathrm{~m}$. Širina donje ploče je $1.6 \mathrm{~m}$. Debljina zida je $30 \mathrm{~cm}$. Visina drugog segmenta je $2.51 \mathrm{~m}$, dužina $3.51 \mathrm{~m}$, a širina ploče je $2.2 \mathrm{~m}$. Treći segment zida je konstantne visine $2.8 \mathrm{~m}$ i dužine $4.20 \mathrm{~m}$. Debljina zida je promjenljiva od $30-50 \mathrm{~cm}$. Donja ploča zida je širine $2.5 \mathrm{~m}$ i debljine $0.25 \mathrm{~m}$. Četvrti segment zida je konstantne visine $3.05 \mathrm{~m}$ i dužine $3.41 \mathrm{~m}$. Debljina zida je promenljiva od $30-50 \mathrm{~cm}$. Donja ploča zida je širine $2.5 \mathrm{~m}$ i debljine $0.25 \mathrm{~m}$. Peti segment zida je konstantne visine $2.8 \mathrm{~m}$ i dužine $5.12 \mathrm{~m}$. Debljina zida je promjenljiva od $30-50 \mathrm{~cm}$. Donja ploča zida je širine $2.5 \mathrm{~m}$ i debljine $0.25 \mathrm{~m}$. Visina šestog segmenta $2.3 \mathrm{~m}$, dužina zida $2.20 \mathrm{~m}$. Širina donje ploče je $2.6 \mathrm{~m}$, a visine $0.25 \mathrm{~m}$. Debljina zida je $30 \mathrm{~cm}$.

Potporni zid PZ3: Zid se sastoji iz dva segmenta. Zbog promjene nivelacije segmenti zida su fundirani na različitim dubinama i različite su visine zidova. Visina prvog segmenta je 4,06m m, dužina zida $2.00 \mathrm{~m}$. Širina donje ploče je $2.6 \mathrm{~m}$. Debljina zida je $30 \mathrm{~cm}$. Zbog spajanja sa zidom koji ide uz osu 2, postoji širi dio zida koji mijenja širinu u zavisnosti od kraja ulice. Visina drugog segmenta je 3,09 m, dužina $3.00 \mathrm{~m}$, a širina ploče je $2.6 \mathrm{~m}$.

Potporni zid PZ4: Zid je konstantne je visine $2.39 \mathrm{~m}, \mathrm{i}$ dugačak je $5.24 \mathrm{~m}$, debljina donje ploče je konstantna $\mathrm{i}$ iznosi $25 \mathrm{~cm}$. Širina ploče je $190 \mathrm{~cm}$, dok je debljina zida promjenljiva od 20 do $60 \mathrm{~cm}$.

Potporni zid PZ5: Zid se sastoji iz pet segmenata i prati nivelaciju puta do platoa kod parkinga. Visina zida prvog segmenta se mijnja od 1,06 m do 2,65 m. Debljina zida je $30 \mathrm{~cm}$, a širina stope od $190 \mathrm{~cm}$. Srednja dva segmenta su konstantne visine od 3,22m. Debljina zida je $30 \mathrm{~cm}$, a širina stope od $230 \mathrm{~cm}$. Visina zida četvrtog segmenta se menja od 3,22 $\mathrm{m}$ do 1,58 m. Debljina zida je $30 \mathrm{~cm}$, a širina stope od $190 \mathrm{~cm}$. Visina zida petog segmenta se menja od 1,58 m do 2,60 m. Debljina zida je $30 \mathrm{~cm}$, a širina stope od $150 \mathrm{~cm}$. Ukupna dužina zida je $32 \mathrm{~m}$. 
Potporni zid PZ6: Zid se sastoji iz osam segmenata i prati pad terena. Zid se izvodi u kampadama od po $2 \mathrm{~m}$. Visina zida je 2,65m. Debljina zida je $30 \mathrm{~cm}$, a širina stope od $170 \mathrm{~cm}$. Ukupna dužina zida je 16,73 m.

\section{ZAKLJUČAK}

Jasno je da zbog ekspanzije građevinarstva nije uvijek moguće izabrati pogodnu lokaciju za izgradnju objekata tako da potporni zidovi, kao jedan od načina da se prevaziđe taj problem, imaju izuzetan značaj. To je značajno naročito kada su u pitanju infrastrukturni objekti kao što su saobraćajnice, kao što je to prikazano u radu.

\section{LITERATURA}

[1] Priručnik za projektovanje puteva u Republici Srbiji, Beograd, 2012.

[2] http://www.gradjevinans.net/index.php/studentskiportal/2014-08-07-07-50-40.html (pristupljeno u septembru 2020.)

[3] Betonske konstrukcije u zgradarstvu, prema Evrokodu, Zoran Brujić

[4] Slika (https://www.espreso.rs/data/images/2018/08/28 /10/417175_koridor-10_ff.jpg)

[5] Sremski Karlovci-wikipedia

Kratka biografija:

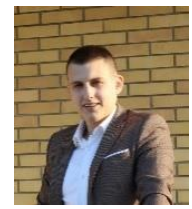

Dejan Palalić rođen je u Banjaluci 1996. god. Master rad na Fakultetu tehničkih nauka iz oblasti Građevinarstva - Putevi, železnice i aerodromi odbranio je 2020. god.

kontakt: dejan.palalic10091996@gmail.com 